\title{
Incidence Rate of Acute Coronary Syndrome Including Acute Myocardial Infarction, Unstable Angina, and Sudden Cardiac Death in Nobeoka City for the Super-Aged Society of Japan
}

\author{
Soshiro Ogata, PhD; Kyohei Marume, MD; Michikazu Nakai, PhD; \\ Ryota Kaichi, MD; Masanobu Ishii, MD; Sou Ikebe, MD; Takayuki Mori, MD; \\ Soichi Komaki, MD; Hiroaki Kusaka, MD; Reiko Toida, MD; \\ Kazumasa Kurogi, MD; Yoshitaka Iwanaga, MD; Takao Yano, MD; \\ Nobuyasu Yamamoto, MD; Yoshihiro Miyamoto, MD
}

\begin{abstract}
Background: This study aimed to calculate incidence rates (IR) of acute coronary syndrome (ACS) including acute myocardial infarction (AMI), unstable angina (UAP), and sudden cardiac death (SCD) in Nobeoka city, Japan.

Methods and Results: This was an observational study based on a city-wide comprehensive registration between 2015 and 2017 in Nobeoka city, Japan, using 2 databases: all patients with cardiogenic out-of-hospital cardiac arrest in Nobeoka city and hospitalized ACS patients from Miyazaki Prefectural Nobeoka Hospital in which all ACS patients in Nobeoka city were hospitalized except for possible rare cases of patients highly unlikely to be hospitalized elsewhere. The IRs of ACS based on the population size of Nobeoka city (125,000 persons), and their age-adjusted IRs by using the direct method and the 2015 model population of Japan were calculated. There were 260 eligible patients hospitalized with first-onset ACS (age [SD]=71.1 [12.4], 34.2\% women) and 107 eligible SCD patients. Crude IRs of hospitalized ACS and SCD patients, and hospitalized AMI and SCD patients, respectively, were 130.2 (183.3 for men, 85.6 for women) and 107.5 (148.4 for men, 73.2 for women) per 100,000. Crude IRs of hospitalized ACS, AMI, and UAP patients, respectively, were 92.3 (132.8 for men, 58.1 for women), 69.6 (97.9 for men, 45.7 for women), and 22.7 (35.0 for men, 12.4 for women) per 100,000.
\end{abstract}

Conclusions: The calculated IRs can be useful in building a health strategy for treating ACS.

Key Words: Acute coronary syndrome; Incidence rate; Observational study

I ncidence rates (IR) of diseases related to major causes health strategies to prepare medical resources and measure effects of intervention on a patient's health status. Acute coronary syndrome (ACS) consisting of acute myocardial infarction (AMI), unstable angina (UAP), and sudden cardiac death (SCD), is a major cause of death and disability worldwide. ${ }^{\mathbf{1} 2}$ The IRs of ACS have been reported in several countries; for example, IRs of ACS per 100,000 population were 417 in the United Kingdom, 214 in France, 407 in Germany, 363 in Italy, 234 in Spain, 165 in Denmark, and 160 in Cyprus. ${ }^{2-4}$ However, there has been of death and disability are essential in developing

\begin{tabular}{l}
\hline Editorial p1731 \\
\hline no report for IRs of ACS and UAP in Japan based on a \\
city-wide population-based design to the best of our \\
knowledge. Previous studies have been limited to reporting \\
IRs of AMI (but not including UAP cases), ${ }^{58}$ of which \\
there have been only 2 population-based studies. \\
Additionally, a previous study has been limited to a ratio \\
of AMI to UAP in Japan (UAP:AMI=1:1.56; UAP was \\
39\% of the total number of AMI and UAP) based on a \\
hospital-based design. ${ }^{\mathbf{5}}$
\end{tabular}

\section{Editorial p1731}

Received December 1, 2020; revised manuscript received April 10, 2021; accepted April 19, 2021; J-STAGE Advance Publication released online June 12, 2021 Time for primary review: 24 days

Department of Preventive Medicine and Epidemiology (S.O.), Center for Cerebral and Cardiovascular Disease Information (M.N., Y.I., Y.M.), National Cerebral and Cardiovascular Center, Suita; Miyazaki Prefectural Nobeoka Hospital, Nobeoka (K.M., R.K., M.I., S.I., T.M., S.K., R.T., K.K., T.Y., N.Y.), Japan; Department of Sport Science, University of Innsbruck, Innsbruck (K.M.), Austria; and National Hospital Organization Kumamoto Medical Center, Kumamoto (H.K.), Japan

Mailing address: Yoshihiro Miyamoto, MD, Center for Cerebral and Cardiovascular Disease Information, National Cerebral and Cardiovascular Center, 6-1 Kishibe-Shimmachi, Suita 564-8565, Japan. E-mail: miyamoty@ncvc.go.jp

All rights are reserved to the Japanese Circulation Society. For permissions, please e-mail: cj@j-circ.or.jp

ISSN-1346-9843 
Mortality rate and IR of coronary artery diseases (CAD) including AMI have been low in Japan compared to many countries. ${ }^{10} \mathrm{Japan}$ is the most aged country in the world, which is going to hold its lead until $2050 .{ }^{11}$ Percentage of people aged $\geq 65$ years in Japan was $\sim 28 \%$ in $2019 .{ }^{11}$ Compared to non-elderly people, the elderly are more likely to develop ACS.,5 Therefore, estimating the number of ACS patients in Japan is difficult based on IRs of ACS in other countries, which therefore prompted us to investigate the IR of ACS in Japan.

A population-based study is a suitable design to accurately calculate IRs of diseases. Nobeoka city, Japan (population size $=$ approximately 125,000 in 2015) is suitable to estimate an accurate IR of hospitalized patients with ACS due to the following reasons. All ACS patients in this city are hospitalized and treated in Miyazaki Prefectural Nobeoka Hospital, except for possible rare cases of patients highly unlikely to be hospitalized elsewhere because Miyazaki Prefectural Nobeoka Hospital is the only emergency and cardiovascular care center in this city as of 2020. Additionally, this city is relatively isolated from other urban centers. Furthermore, there is a database registering all patients with out-of-hospital cardiac arrest (OHCA) in Nobeoka city. Thus, we aimed to calculate the IRs of hospitalized patients with ACS including AMI and UAP, and SCD in Nobeoka city, Japan, based on a citywide comprehensive registration.

\section{Methods}

\section{Design and Study Population}

The present study was conducted in Nobeoka, a city in the eastern part of Kyusyu island with a population of approximately 125,000 based on a census conducted in 2015 . Nobeoka constitutes a highly suitable setting for epidemiological research because the city is relatively isolated from other urban centers, and medical care is practically self-contained within the city. We used the following 2 databases. First, the present study was based on data from a database between January 2015 and December 2017 from the Nobeoka Heart Study, a study using city-wide comprehensive registration consisting of a cohort of inpatients with ACS and those with heart failure in Miyazaki Prefectural Nobeoka Hospital. The Miyazaki Prefectural Nobeoka Hospital is the only regional high-quality acute hospital in Nobeoka city that has been designated by the municipal government; it has 410 hospital beds and provides the majority of medical care for the population. ${ }^{12}$ The hospital has been the only facility with a catheter laboratory and provided intensive care including percutaneous coronary intervention for ACS patients in the city during the study period. ${ }^{12}$ General physicians and ambulance paramedics referred all their patients with suspected ACS to the hospital. Additionally, the nearest facility with a catheter laboratory is $\sim 60 \mathrm{~km}$ away from our hospital in another prefecture. The second nearest facility with a catheter laboratory is $\sim 90 \mathrm{~km}$ from our hospital in another city in Miyazaki prefecture. Therefore, it is highly unlikely that cardiogenic OHCA patients in Nobeoka city were transported by ambulance to facilities other than our hospital; all ACS patients in this city have been hospitalized and treated in the hospital except possible rare cases of patients highly unlikely to be hospitalized elsewhere. The environment features of this study enabled us to calculate accurate IRs of hospitalized ACS patients in Nobeoka city.
Additionally, the present study used a database between January 2015 and December 2017 managed by the Nobeoka Medical Control Consultative Committee for Emergency Transportation, which registered all OHCA and other severe cases in Nobeoka transported by ambulance. This committee classifies each OHCA case as cardiogenic or not by biochemical examination of blood including troponin $\mathrm{T}$ at the time of admission, blood gas findings, ECG findings during transport and at the time of admission, and post-mortem computed tomography (PMCT). Thus, this database allowed us to count all cardiogenic OHCA cases. Note that this committee consists of $\sim 10$ medical doctors including emergency physicians, cardiologists, cardiovascular surgeons, surgeons, internists, and physicians of the medical association, as well as $\sim 8$ emergency ambulance attendants.

This study was approved by the institutional review board of Miyazaki Prefectural Nobeoka Hospital (20190911-1 and 20191004-1) and the National Cerebral and Cardiovascular Center (No. M30-007). As individual patients were not identified, obtaining individual consent for the study was waived. We publicized the study, however, by posting an easy-to-understand summary of the study on a notice board and website of the Miyazaki Prefectural Nobeoka Hospital and on the website of the National Cerebral and Cardiovascular Center; patients were able to withdraw from the study if they desired.

\section{Findings for Patients Hospitalized With ACS in Miyazaki Prefectural Nobeoka Hospital}

We retrospectively reviewed consecutive patients with ACS who had been hospitalized in Miyazaki Prefectural Nobeoka Hospital, aged $\geq 30$ years old between January 2015 and December 2017. First, we reviewed patients whose primary disease had been registered as ACS, including AMI and UAP, to exclude patients admitted to the hospital primarily due to diseases other than ACS. In this hospital, cardiologists diagnosed ACS according to guidelines published by the Japanese Circulation Society for Diagnosis and Treatment of Acute Coronary Syndrome. ${ }^{13}$ To diagnose ACS, the cardiologists examined patients for the following: presence of ACS symptoms (e.g., chest pain); vital signs (e.g., blood pressure, respiratory sound, cardiac sound, and so on); presence of persistent ST-segment elevation, ST-segment depression, and negative $\mathrm{T}$-wave by 12-lead electrocardiogram (ECG); presence of abnormal wall motion by echocardiography; and myocardial biomarkers including cardiac troponin, creatine kinase MB, and so on. They diagnosed patients with AMI when a rise and/or fall of cardiac biomarkers such as troponin $\mathrm{T}$ was found, with at least 1 value above the $99^{\text {th }}$ percentile of the upper reference limit, and in the presence of myocardial ischemia indicators including AMI symptoms, ECG changes, and imaging findings of new loss of viable myocardium or new regional wall-motion abnormalities. They diagnosed patients with UAP when persistent STsegment elevation was not observed, myocardial biomarkers were normal, and UAP symptoms referring to Braunwald Classification were observed. ${ }^{14}$

Second, the complete records (including inpatient and outpatient records) of the possible ACS patients were manually reviewed to validate the diagnosis of ACS by the cardiologist according to the guidelines. ${ }^{13}$ We found 513 ACS cases. Of these, we excluded 209 cases of nonNobeoka residents and 44 cases due to ACS histories. 


\begin{tabular}{|c|c|c|}
\hline & $\begin{array}{c}\text { Men } \\
(n=171)\end{array}$ & $\begin{array}{l}\text { Women } \\
(n=89)\end{array}$ \\
\hline \multicolumn{3}{|l|}{ Continuous variables, median (IQR) } \\
\hline Age, years & $67.0(60.0,75.5)$ & $79.0(73.0,85.0)$ \\
\hline Body mass index, $\mathrm{kg} / \mathrm{m}^{2}$ & $23.5(21.7,26.6)$ & $22.4(19.7,25.3)$ \\
\hline Systolic blood pressure, $\mathrm{mmHg}$ & $146.0(126.5,163.0)$ & $144.0(126.5,165.5)$ \\
\hline Diastolic blood pressure, $\mathrm{mmHg}$ & $86.0(73.0,98.0)$ & $79.0(69.0,88.0)$ \\
\hline $\mathrm{HbA} 1 \mathrm{c}, \%$ & $5.9(5.5,6.6)$ & $5.8(5.5,6.3)$ \\
\hline $\mathrm{HDL}$ cholesterol, mg/dL & $45.0(38.0,54.0)$ & $53.0(44.0,65.0)$ \\
\hline LDL cholesterol, mg/dL & $125.0(102.0,150.0)$ & $124.0(104.0,148.5)$ \\
\hline Total cholesterol, mg/dL & $198.0(169.0,226.8)$ & $198.5(174.5,228.5)$ \\
\hline Creatine kinase, IU/L & $182.0(88.2,1,207.5)$ & $186.5(97.5,621.8)$ \\
\hline eGFR, $\mathrm{mL} / \mathrm{min} / 1.73 \mathrm{~m}^{2}$ & $62.8(52.5,75.1)$ & $57.3(44.5,72.9)$ \\
\hline \multicolumn{3}{|l|}{ Categorical variables, $\mathrm{n}(\%)$} \\
\hline \multicolumn{3}{|l|}{ Age groups } \\
\hline Non-old age (<65 years) & $69(40.4)$ & $5(5.6)$ \\
\hline Pre-old age (65-74 years) & $52(30.4)$ & $24(27.0)$ \\
\hline Old age (75-89 years) & $49(28.7)$ & $50(56.2)$ \\
\hline Super-old age ( $\geq 90$ years) & $1(0.6)$ & $10(11.2)$ \\
\hline \multicolumn{3}{|l|}{ ACS types } \\
\hline Acute myocardial infarction & $126(73.7)$ & $70(78.7)$ \\
\hline Unstable angina & $45(26.3)$ & $19(21.3)$ \\
\hline Smoking+ & $103(60.2)$ & $9(10.1)$ \\
\hline Hypertension+ & $127(74.3)$ & $67(75.3)$ \\
\hline Dyslipidemia+ & $117(68.4)$ & $58(65.2)$ \\
\hline Diabetes+ & $53(31.0)$ & $25(28.1)$ \\
\hline Percutaneous coronary intervention+ & $144(84.2)$ & $69(77.5)$ \\
\hline In-hospital death+ & $13(7.6)$ & $9(10.1)$ \\
\hline
\end{tabular}

+, presence; ACS, acute coronary syndrome; eGFR, estimated glomerular filtration rate; HbA1c, hemoglobin A1c; HDL, high-density lipoprotein; IQR, interquartile range; LDL, low-density lipoprotein.

Therefore, 260 ACS patients were included in the present analyses.

\section{Patient Findings for SCD}

We retrospectively and consecutively reviewed all patients who suffered from cardiogenic OHCA by using medical records of our hospital and the database, managed by Nobeoka Medical Control Consultative Committee for Emergency Transportation, between January 2015 and December 2017. This committee classifies each OHCA case as cardiogenic or not by biochemical examination of blood including troponin $\mathrm{T}$ at the time of admission, blood gas findings, ECG findings during transport and at the time of admission, and PMCT. Additionally, this committee consists of $\sim 10$ medical doctors including emergency physicians, cardiologists, cardiovascular surgeons, surgeons, internists, and physicians of the medical association, as well as $\sim 8$ emergency ambulance attendants. We defined SCD cases as patients who died within $24 \mathrm{~h}$ of when the emergency medical service recognized the cardiogenic OHCA incidence.

\section{Demographic and Clinical Data}

We collected the following information from medical records at the time of patient hospital admission: age, sex, body mass index (BMI), systolic blood pressure (SBP), diastolic blood pressure (DBP), HbA1c, high-density lipoprotein (HDL) cholesterol, low-density lipoprotein (LDL) cholesterol, total cholesterol, creatine kinase, estimated glomerular filtration rate (eGFR), smoking status, medical histories of hypertension, dyslipidemia, and diabetes, and history of percutaneous coronary intervention. Age was categorized into the following groups: non-old age (aged 30-64 years), pre-old age (aged 65-74 years), and old age (aged 75-89 years) or super-old age (aged $\geq 90$ years) according to the Japan Geriatrics Society. ${ }^{15}$ Additionally, we collected the population size data for people aged $\geq 30$ years in Nobeoka city between 2015 and 2017 with 1-year age intervals. ${ }^{16}$

\section{Statistical Analyses}

We summarized patient characteristics by using median with interquartile range (IQR) for continuous variables and number and proportion for categorical variables. Age group- (ages 30-64, 65-74, and $\geq 75$ years) and sex- specific IRs were calculated per 100,000 person-years based on the population size of Nobeoka city for people aged $\geq 30$ years. Age-adjusted IRs were calculated by using the direct method of standardization as follows. Each age groupspecific IR in Nobeoka city was multiplied by the proportion of the standard population corresponding to the same age group. Age group-specific results were summed up to obtain the age-adjusted IRs. Note that the standard population of the present study was the 2015 model population of Japan (Supplementary Table 1). ${ }^{17}$

Incidence rate ratios (IRR) of ACS, AMI, and UAP by 
Table 2. Characteristics of All Patients Who Suffered From Cardiogenic Out-of-Hospital Cardiac Arrest Between 2015 and 2017 in Nobeoka City, Japan

\begin{tabular}{|c|c|c|}
\hline & $\begin{array}{c}\text { Men } \\
(n=79)\end{array}$ & $\begin{array}{c}\text { Women } \\
(n=47)\end{array}$ \\
\hline Age, years, median (IQR) & $78.0(65.5,85.5)$ & $81.0(72.5,87.5)$ \\
\hline \multicolumn{3}{|l|}{ Age groups, $\mathbf{n}(\%)$} \\
\hline Non-old age (<65 years) & $18(22.8)$ & $7(14.9)$ \\
\hline Pre-old age (65-74 years) & $16(20.3)$ & $8(17.0)$ \\
\hline Old age (75-89 years) & $38(48.1)$ & $21(44.7)$ \\
\hline Super-old age ( $\geq 90$ years) & $7(8.9)$ & $11(23.4)$ \\
\hline Transported to Miyazaki Prefectural Nobeoka Hospital+, n (\%) & $76(96.2)$ & $44(93.6)$ \\
\hline \multicolumn{3}{|l|}{ Citizenship, n (\%) } \\
\hline Nobeoka citizens & 74 (93.7) & $42(89.4)$ \\
\hline Other cities & $2(2.5)$ & $2(4.3)$ \\
\hline Unknown ${ }^{\dagger}$ & $3(3.8)$ & $3(6.4)$ \\
\hline Medical history of ACS & $1(1.3)$ & $0(0)$ \\
\hline \multicolumn{3}{|l|}{ SCD+, n (\%) } \\
\hline Any SCD & $69(87.3)$ & $44(93.6)$ \\
\hline SCD in non-Nobeoka citizens & $2(2.5)$ & $2(4.3)$ \\
\hline SCD used to calculate incidence rate $\ddagger$ & 65 (82.3) & $42(89.4)$ \\
\hline
\end{tabular}

tThe reason for unknown citizenship was that these 6 patients were transported to hospitals other than Miyazaki Prefectural Nobeoka Hospital and therefore we were unable to obtain residence information. ‡Patients with SCD who were transported to Miyazaki Prefectural Nobeoka Hospital, Nobeoka citizens without a medical history of ACS, and patients aged $\geq 30$ years were used to calculate the incidence rate of ACS including SCD. SCD, sudden cardiac death. Other abbreviations as in Table 1.

\begin{tabular}{|c|c|}
\hline A) Hospitalized ACS cases & B) SCD cases \\
\hline $\begin{array}{l}\text { Patients with hospitalized ACS in Miyazaki } \\
\text { Prefectural Nobeoka Hospital between January } \\
2015 \text { and December } 2017 \text { ( } 513 \text { cases) }\end{array}$ & $\begin{array}{l}\text { Patients with cardiogenic OHCA who were transported by ambulance in } \\
\text { Nobeoka between January } 2015 \text { and December } 2017 \text { ( } 126 \text { cases) }\end{array}$ \\
\hline$\rightarrow \begin{array}{l}\text { Non-Nobeoka residents ( } 209 \text { cases) } \\
\text { Patients with ACS histories ( } 44 \text { cases) }\end{array}$ & $\rightarrow \begin{array}{l}\begin{array}{l}\text { Patients transported to hospitals other than Miyazaki Prefectural } \\
\text { Nobeoka Hospital (6 cases) }\end{array} \\
\end{array}$ \\
\hline \multirow[t]{3}{*}{$\begin{array}{l}\text { Patients with first-ever hospitalized ACS } \\
\text { ( } 260 \text { cases) }\end{array}$} & $\begin{array}{l}\text { Patients transported to Miyazaki Prefectural Nobeoka Hospital } \\
\text { (120 cases) }\end{array}$ \\
\hline & $\begin{array}{l}\text { Patients survived }>24 \text { hours of when the emergency medical service } \\
\text { recognized the cardiogenic OHCA incidence ( } 7 \text { cases) }\end{array}$ \\
\hline & $\begin{array}{l}\text { SCD cases ( } 113 \text { cases including } 4 \text { non-Nobeoka residents, } 1 \text { case aged < } \\
30 \text { years old, and } 1 \text { case with ACS history.) }\end{array}$ \\
\hline
\end{tabular}

Figure 1. Patient flow diagram. ACS, acute coronary syndrome; SCD, sudden cardiac death; OHCA, out-of-hospital cardiac arrest.

age group were obtained by generalized linear models (GLM) assuming Poisson distribution with logarithm population size as offset terms. Additionally, we also performed GLM to estimate IRR of ACS by sex by calculating IRs of ACS within 10-year age divisions. All statistical analyses were performed by using $\mathrm{R}$ statistical software version 4.0 (The R Foundation, Vienna, Austria). ${ }^{18}$ The significance tests were 2-sided and the significance level for all analyses was $\mathrm{P}$ value $<0.05$.

\section{Results}

In Nobeoka city, we found 260 eligible patients hospitalized with first-onset ACS (age [SD]=71.1 [12.4], 34.2\% women) consisting of $75.4 \%$ AMI and $24.6 \%$ UAP. In the present study patients with ACS, the median age was 67 years for men and 79 years for women. ACS patients aged $\geq 75$ years were $29.3 \%$ in men and $67.4 \%$ in women. Detailed patient characteristics are summarized in Table 1. Additionally, there were 126 patients who suffered from cardiogenic OHCA who were transported by ambulance in Nobeoka city (Table 2). Of the 126 patients, $120(95.2 \%)$ were transported to our hospital. There were 113 SCD cases including 4 patients who did not live in Nobeoka, 1 patient aged $<30$ years, and 1 patient who had already been hospitalized in our hospital due to ACS. Therefore, 107 SCD patients were analyzed for IRs. Figure 1 shows a patient flow diagram of the present study.

We showed crude IRs per 100,000 of hospitalized patients with ACS, AMI, and UAP, hospitalized patients with ACS and SCD, and hospitalized patients with AMI and SCD in Nobeoka city between 2015 and 2017 (Table 3 
Table 3. IRs of Hospitalized Patients With ACS Including AMI and UAP, and SCD in Men of Nobeoka City, Japan, Between 2015 and 2017

\begin{tabular}{|c|c|c|c|c|c|}
\hline Age group & $\begin{array}{l}\text { Non-old age } \\
\text { (30-64 years) }\end{array}$ & $\begin{array}{l}\text { Pre-old age } \\
\text { (65-74 years) }\end{array}$ & $\begin{array}{l}\text { Old-age and } \\
\text { super-old age } \\
(\geq 75 \text { years })\end{array}$ & $\begin{array}{c}\text { All ages } \\
(\geq 30 \text { years })\end{array}$ & $\begin{array}{l}\text { Age-standardized IR } \\
\text { calculated by using } \\
\text { the Japanese model } \\
\text { population in } 2015\end{array}$ \\
\hline \multicolumn{6}{|l|}{ Men } \\
\hline Person-years (3 years) & 79,548 & 26,218 & 22,959 & 128,725 & NA \\
\hline \multicolumn{6}{|l|}{ Hospitalized ACS+SCD } \\
\hline Incident N & 79 & 68 & 89 & 236 & NA \\
\hline $\mathrm{IR}$ & $99.3(78.6,123.8)$ & $259.4(201.4,328.8)$ & $387.6(311.3,477)$ & $183.3(160.7,208.3)$ & $181.4(143.7,226.1)$ \\
\hline IRR & 1=Ref. & $2.6(1.9,3.6)$ & $3.9(2.9,5.3)$ & NA & NA \\
\hline \multicolumn{6}{|l|}{ Hospitalized ACS } \\
\hline Incident N & 69 & 52 & 50 & 171 & NA \\
\hline $\mathrm{IR}$ & $86.7(67.5,109.8)$ & $198.3(148.1,260.1)$ & $217.8(161.6,287.1)$ & $132.8(113.7,154.3)$ & $131.4(99.7,170.2)$ \\
\hline IRR & 1=Ref. & $2.3(1.6,3.3)$ & $2.5(1.7,3.6)$ & NA & NA \\
\hline \multicolumn{6}{|l|}{ Hospitalized AMI+SCD } \\
\hline Incident N & 64 & 53 & 74 & 191 & NA \\
\hline IR & $80.5(62,102.7)$ & $202.2(151.4,264.4)$ & $322.3(253.1,404.6)$ & $148.4(128.1,171)$ & $147(113.3,187.6)$ \\
\hline IRR & 1=Ref. & $2.5(1.7,3.6)$ & $4.0(2.9,5.6)$ & NA & NA \\
\hline \multicolumn{6}{|l|}{ Hospitalized AMI } \\
\hline Incident N & 54 & 37 & 35 & 126 & NA \\
\hline $\mathrm{IR}$ & $67.9(51,88.6)$ & $141.1(99.4,194.5)$ & $152.4(106.2,212)$ & $97.9(81.5,116.5)$ & $97.0(70.1,130.9)$ \\
\hline IRR & 1=Ref. & $2.1(1.4,3.1)$ & $2.2(1.5,3.4)$ & NA & NA \\
\hline \multicolumn{6}{|l|}{ Hospitalized UAP } \\
\hline Incident N & 15 & 15 & 15 & 45 & NA \\
\hline $\mathrm{IR}$ & $18.9(10.6,31.1)$ & $57.2(32,94.4)$ & $65.3(36.6,107.8)$ & $35.0(25.5,46.8)$ & $34.5(19.3,56.9)$ \\
\hline IRR & 1=Ref. & $3.0(1.5,6.3)$ & $3.5(1.7,7.1)$ & NA & NA \\
\hline
\end{tabular}

AMI, acute myocardial infarction; IR, incidence rate; IRR, incidence rate ratio; NA, not applicable; Ref., reference; UAP, unstable angina. Other abbreviations as in Tables 1,2.

Table 4. IRs of Hospitalized Patients With ACS Including AMI and UAP, and SCD in Women of Nobeoka City, Japan, Between 2015 and 2017

Age group

Women

Person-years (3 years)

Hospitalized ACS+SCD

Incident $\mathrm{N}$

IR

IRR

Hospitalized ACS

Incident $\mathrm{N}$

IR

IRR

Hospitalized AMI+SCD

Incident N

IR

IRR

Hospitalized AMI

Incident $\mathrm{N}$

IR

IRR

Hospitalized UAP

Incident $\mathrm{N}$

IR

IRR

Non-old age
(30-64 years)

83,045

11

$13.2(6.6,23.7)$

$1=$ Ref.

5

$6.0(2.0,14.1)$

$1=$ Ref.

Pre-old age

(65-74 years)

29,858

32

$107.2(73.3,151.3)$

$8.1(4.2,16.8)$

24

$80.4(51.5,119.6) \quad 149.4(114,192.3)$

$13.4(5.5,39.6)$

$24.8(11.0,71.0)$

77

$83.7(54.2,123.6)$

$7(3.4,15.2)$

$191.7(151.3,239.6)$

$15.9(8.7,32.8)$

17

$4.8(1.3,12.3)$

$1=$ Ref.

$56.9(33.2,91.2)$

$11.8(4.4,41.1)$

49

$122.0(90.2,161.3)$

$25.3(10.3,83.9)$

11

$27.4(13.7,49.0)$

$22.7(4.4,415.7)$

\begin{tabular}{rlc}
1 & \multicolumn{1}{c}{7} & 11 \\
$1.2(0,6.7)$ & $23.4(9.4,48.3)$ & $27.4(13.7,49.0)$ \\
1=Ref. & $19.5(3.5,363.9)$ & $22.7(4.4,415.7)$
\end{tabular}

Age-standardized IR calculated by using the Japanese model population in 2015

Abbreviations as in Tables 1-3.

$12.4(7.5,19.4)$

NA

NA

$68(49.6,92.1)$

NA

NA $58.1(46.7,71.5) \quad 45.9(31.5,66.1)$

NA NA

\section{NA}

$57.8(41.1,80.4)$

NA

NA

$35.7(23.3,54.0)$

NA

$(35.6,57.8)$

NA

$10.1(4.2,22.2)$

NA

NA 


\begin{tabular}{|c|c|c|c|c|c|}
\hline Age group & $\begin{array}{l}\text { Non-old age } \\
\text { (30-64 years) }\end{array}$ & $\begin{array}{l}\text { Pre-old age } \\
\text { (65-74 years) }\end{array}$ & $\begin{array}{l}\text { Old-age and } \\
\text { super-old age } \\
\text { ( } \geq 75 \text { years) }\end{array}$ & $\begin{array}{c}\text { All ages } \\
(\geq 30 \text { years })\end{array}$ & $\begin{array}{l}\text { Age-standardized IR } \\
\text { calculated by using } \\
\text { the Japanese model } \\
\text { population in } 2015\end{array}$ \\
\hline \multicolumn{6}{|l|}{ Men and women } \\
\hline Person-years ( 3 years) & 162,593 & 56,076 & 63,129 & 281,798 & NA \\
\hline \multicolumn{6}{|l|}{ Hospitalized ACS+SCD } \\
\hline Incident N & 90 & 100 & 177 & 367 & NA \\
\hline $\mathrm{IR}$ & $55.4(44.5,68)$ & $178.3(145.1,216.9)$ & $280.4(240.6,324.9)$ & $130.2(117.2,144.3)$ & $124.7(96.6,159.1)$ \\
\hline IRR & 1=Ref. & $3.2(2.4,4.3)$ & $5.1(3.9,6.6)$ & NA & NA \\
\hline \multicolumn{6}{|l|}{ Hospitalized ACS } \\
\hline Incident N & 74 & 76 & 110 & 260 & NA \\
\hline $\mathrm{IR}$ & $45.5(35.7,57.1)$ & $135.5(106.8,169.6)$ & $174.2(143.2,210.0)$ & $92.3(81.4,104.2)$ & $88.6(65.6,118.1)$ \\
\hline IRR & 1=Ref. & $3.0(2.2,4.1)$ & $3.8(2.9,5.2)$ & NA & NA \\
\hline \multicolumn{6}{|l|}{ Hospitalized AMI+SCD } \\
\hline Incident N & 74 & 78 & 151 & 303 & NA \\
\hline IR & $45.5(35.7,57.1)$ & $139.1(109.9,173.6)$ & $239.2(202.6,280.5)$ & $107.5(95.8,120.3)$ & $102.4(77.2,134)$ \\
\hline IRR & 1=Ref. & $3.1(2.2,4.2)$ & $5.3(4,7)$ & NA & NA \\
\hline \multicolumn{6}{|l|}{ Hospitalized AMI } \\
\hline Incident N & 58 & 54 & 84 & 196 & NA \\
\hline $\mathrm{IR}$ & $35.7(27.1,46.1)$ & $96.3(72.3,125.6)$ & $133.1(106.1,164.7)$ & $69.6(60.2,80.0)$ & $66.3(46.7,92.4)$ \\
\hline IRR & 1=Ref. & $2.7(1.9,3.9)$ & $3.7(2.7,5.2)$ & NA & NA \\
\hline \multicolumn{6}{|l|}{ Hospitalized UAP } \\
\hline Incident $\mathrm{N}$ & 16 & 22 & 26 & 64 & NA \\
\hline IR & $9.8(5.6,16.0)$ & $39.2(24.6,59.4)$ & $41.2(26.9,60.3)$ & $22.7(17.5,29.0)$ & $22.3(11.8,39.5)$ \\
\hline IRR & 1=Ref. & $4(2.1,7.7)$ & $4.2(2.3,8.0)$ & NA & NA \\
\hline
\end{tabular}

Abbreviations as in Tables 1-3.

for men, Table 4 for women, and Table 5 for both sexes). Additionally, we showed crude IRs of hospitalized patients with ACS and SCD, and hospitalized patients with ACS according to 10-year age divisions in Figures 2 and 3. For men, crude IRs $(95 \% \mathrm{CI})$ of hospitalized ACS and SCD were $99.3(78.6,123.8), 259.4$ (201.4, 328.8), and 387.6 $(311.3,477)$, respectively, in those aged 30 to 64,65 to 74 , and 75 and over (Table 3). Their IRRs $(95 \%$ CI) were 2.6 $(1.9,3.6, \mathrm{P}<0.001)$ in those aged 65 to 74 , and 3.9 (2.9, 5.3, $\mathrm{P}<0.001)$ in those aged 75 years and older, compared to those aged 30 to 64 years. For women, crude IRs $(95 \% \mathrm{CI})$ of hospitalized ACS and SCD were 13.2 (6.6, 23.7), 107.2 (73.3, 151.3), and 219.1 (175.7, 269.9), respectively, in those aged 30 to 64, 65 to 74, and 75 and over (Table 4). Their IRRs $(95 \% \mathrm{CI})$ were $8.1(4.2,16.8, \mathrm{P}<0.001)$ in those aged 65 to 74 , and $16.5(9.2,32.8, \mathrm{P}<0.001)$ in those aged 75 years and older, compared to those aged 30 to 64 years. Additionally, crude IRs of hospitalized ACS and SCD were higher in men than in women (IRR [95\% CI]: $2.6[2.1$, 3.2], $\mathrm{P}<0.001$, Figure 2).

Crude IRs $(95 \%$ CI) of hospitalized men with ACS were 86.7 (67.5, 109.8), 198.3 (148.1, 260.1), and 217.8 (161.6, 287.1 ), respectively, in those aged $30-64,65-74$, and $\geq 75$ years (Table 3). IRRs (95\% CI) of hospitalized patients with ACS were $2.3(1.6,3.3, \mathrm{P}<0.001)$ in those aged 65-74 years, and $2.5(1.7,3.6, \mathrm{P}<0.001)$ in those aged $\geq 75$ years, compared to those aged 30-64 years. Crude IRs $(95 \% \mathrm{CI})$ of hospitalized women with ACS were 6 (2.0, 14.1), 80.4 $(51.5,119.6)$, and $149.4(114,192.3)$, respectively, in those aged 30-64, 65-74, and $\geq 75$ years (Table 4). IRRs $(95 \% \mathrm{CI})$ of hospitalized patients with ACS were 13.4 (5.5, 39.6,

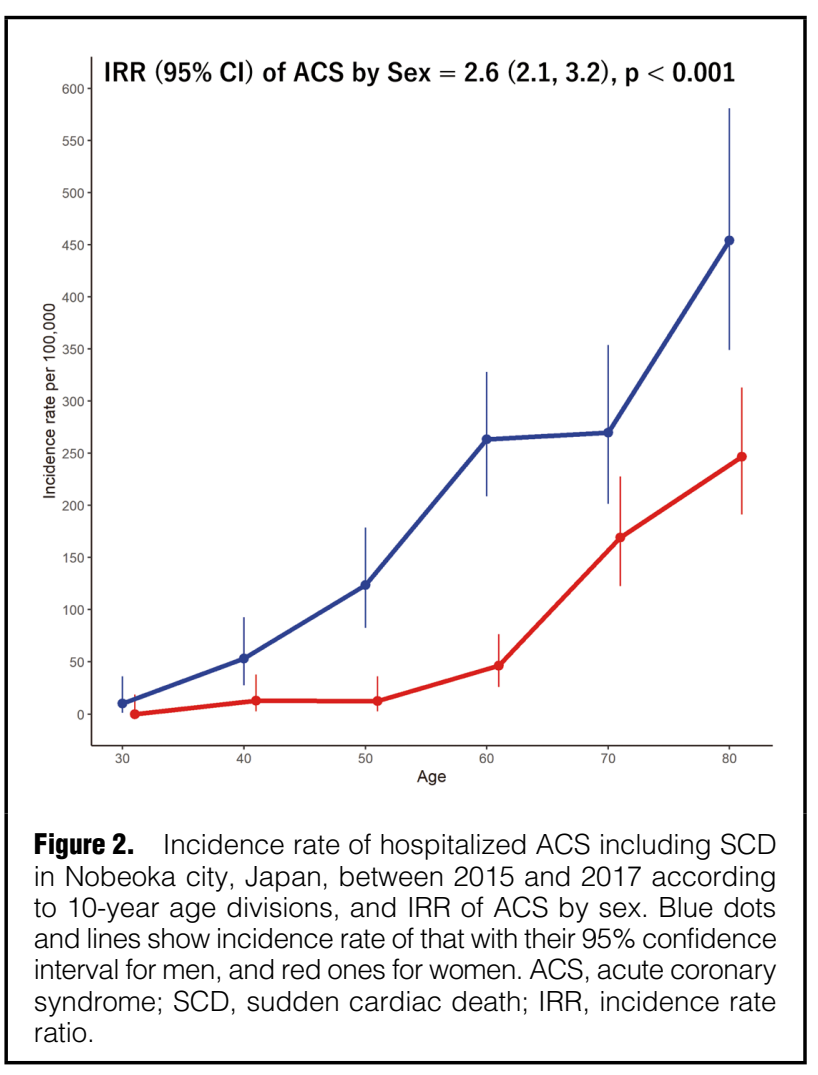




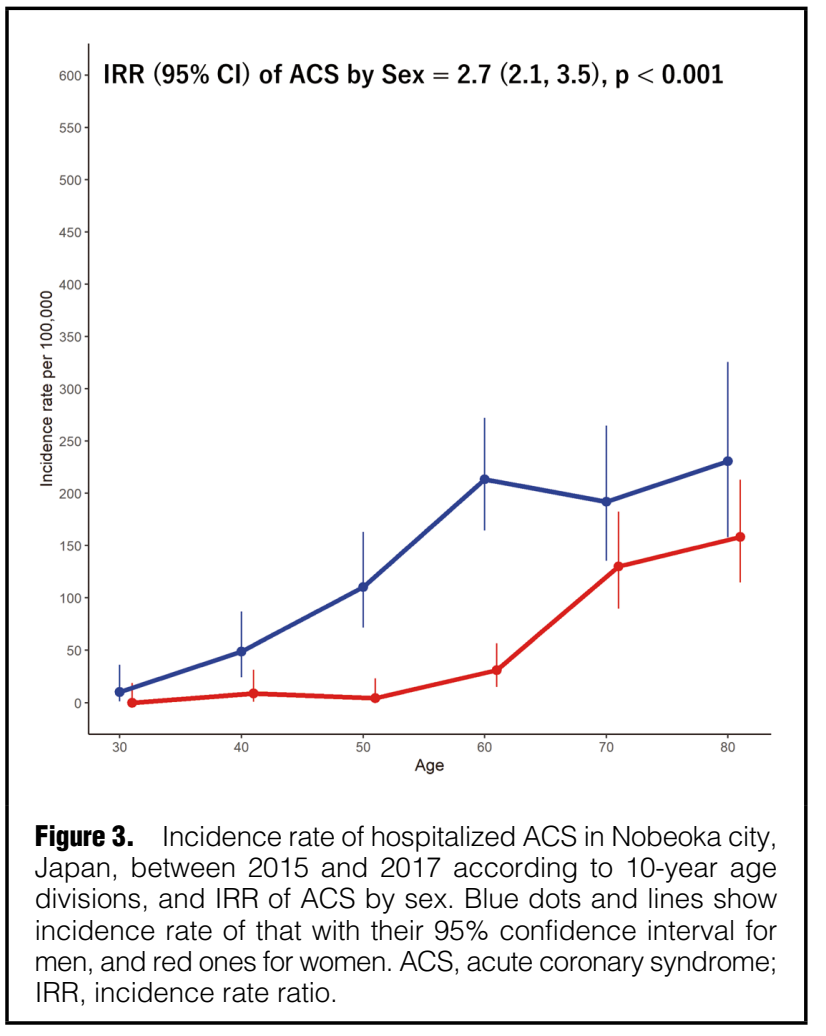

$\mathrm{P}<0.001)$ in those aged 65-74 years, and $24.8(11,71$, $\mathrm{P}<0.001)$ in those aged $\geq 75$ years, compared to those aged 30-64 years. Additionally, crude IRs of hospitalized patients with ACS were higher in men than in women (IRR [95\% CI]: 2.7 [2.1, 3.5], $\mathrm{P}<0.001$; Figure 3).

We summarized age-adjusted IRs per 100,000 of hospitalized patients with ACS, AMI, and UAP, hospitalized patients with ACS and SCD, and hospitalized patients with AMI and SCD using the 2015 model population of Japan (Table 3 for men, Table 4 for women, and Table 5 for both sexes). Crude IRs within 5-year intervals are also summarized in Supplementary Tables 2-6.

\section{Discussion}

\section{Summary}

The present study showed that crude IRs of hospitalized patients with ACS and SCD, and hospitalized patients with AMI and SCD, respectively, were 130.2 (183.3 for men, 85.6 for women) and 107.5 (148.4 for men, 73.2 for women) per 100,000 in Nobeoka, Japan, between 2015 and 2017. Additionally, crude IRs of hospitalized patients with ACS, AMI, and UAP, respectively, were 92.3 (132.8 for men; 58.1 for women), 69.6 (97.9 for men; 45.7 for women), and 22.7 (35.0 for men; 12.4 for women), also showing $75.4 \%$ AMI and $24.6 \%$ UAP of the ACS incidence. The IRs were higher in elderly groups than in the non-elderly groups. Higher IRs of ACS were observed in men than in women. To the best of our knowledge, the present study was the first paper showing crude and age-adjusted IRs of ACS including AMI, UAP, and SCD in Japan using a citywide comprehensive registration and the 2015 model population of Japan.

\section{Comparing IR of ACS Between Nobeoka, Japan and Other} Countries

The crude IR of hospitalized patients with ACS, and hospitalized patients with ACS and SCD in Nobeoka city, Japan, between 2015 and 2017 were lower than that seen in other countries. Crude IRs of ACS per 100,000 were 234 (331 for men and 137 for women) when including SCD and 165 (240 for men and 90 for women) when excluding SCD in Aarhus, Denmark between 2000 and $2002 .{ }^{2}$ Crude IRs of hospitalized patients with ACS was 160 (282 for men and 41 for women) in Nicosia, Cyprus in $2009,{ }^{4}$ and 214.9 in Czech Republic in 2012. ${ }^{19}$ Age-adjusted IRs of hospitalized patients with ACS were 345 for men and 70 for women in Western Australia in 2007. ${ }^{20}$ Additionally, the present study showed higher IRs of ACS in people aged $\geq 75$ years (Tables 3-5), which was consistent with previous studies. 2,20

IRs of AMI and UAP were lower in Japan than in other countries. Crude IRs of hospitalized patients with AMI and hospitalized patients with UAP, respectively, were 69.6 (97.9 for men, 45.7 for women) and 22.7 (35.0 for men, 12.4 for women) per 100,000 in Nobeoka. In Czech Republic in 2012, crude IRs of hospitalized patients with AMI and hospitalized patients with UAP, respectively, were 168 and 46.9.19 In Aarhus, Denmark, between 2000 and 2002, crude IRs of AMI and UAP excluding SCD, respectively, were 126 and $39 .^{2}$ Age-adjusted IRs in men and women, respectively, were $\sim 230$ and 90 for hospitalized patients with AMI, and $\sim 110$ and 75 for hospitalized patients with UAP in Western Australia in 2007. ${ }^{20}$ In 30 European countries, crude IR of hospitalized patients with AMI was $\sim 190$ per 100,000 persons. ${ }^{21}$

The present IRs of ACS in Nobeoka were lower than in other countries, which is similar to lower IRs of AMI in Japan being historically observed compared to other countries' IRs of AMI in monitoring trends and determinants in cardiovascular disease (MONICA study). ${ }^{\mathbf{1} 22}$ Possible reasons of such differences in IR and mortality of AMI may be due to lower CAD risk factors including lower levels of BMI, LDL-c, and dietary intake of saturated fatty acid, and higher levels of HDL-cholesterol and dietary intake of omega-3 fatty acid, ${ }^{23}$ though this has not yet been conclusive. $^{24}$

\section{Comparing IRs of AMI Between Nobeoka and Other Areas in Japan}

Previous population-based, age-specific annual IRs of AMI in Japan were similar to the present IRs of AMI, considering that the ratio of the IR of AMI in the highest prefecture to the lowest prefecture was 2.0 in Japan. ${ }^{25}$ The present study showed that crude IRs of hospitalized patients with AMI and SCD were 139.1 (202.2 for men, 83.7 for women) in people aged between 65 and 74 years in Nobeoka. Previous studies using a population-based registry in Japan showed the following crude IRs of AMI and SCD: 102.9-155.4 (135.4-200.5 for men and 63.5-151.9 for women) in people aged between 65 and 74 years in Takashima of Shiga prefecture between 1990 and 2001;5 and $126.1-146.4$ in men and $24.4-50.3$ in women aged between 60 and 69 years in Ninohe city and Kuji city of Iwate prefecture between 2006 and 2014 . $^{6}$

This is the first study reporting age-specific IRs of ACS including AMI, UAP, and SCD based on a populationbased methodology in Japan. To the best of our knowledge, there were only 2 population-based studies reporting 
age-specific annual IRs of AMI (but not including UAP cases) in Japan. ${ }^{5,6}$ The other previous studies reporting IRs of AMI were based on hospital-based designs. For example, a previous cohort study in Japan showed that IRs of AMI were 202.1 in men and 45.8 in women aged between 60 and 69 years; the baseline was between April 1992 and 1995 with a mean follow up of 10 years. ${ }^{7}$ Furthermore, crude IRs of AMI were reported to be 27.3, 131.7, and 181.1 in men aged $<65$, between 65 and 74 , and $\geq 75$ years, respectively, and 4.2, 44.0, and 102.2 in women aged $<65$, between 65 and 74 , and $\geq 75$ years, respectively, in Yamagata prefecture between 2003 and 2010.8 Those previous IRs of AMI were different from the present IRs of AMI (i.e., hospitalized patients with AMI including SCD cases, Tables 3,4), possibly due to varying definitions of AMI, study year, and especially study design type. Although the previous studies used hospital-based designs, the present study used a population-based approach. In fact, those previous IRs of AMI were similar to the present IRs of hospitalized patients with AMI only (i.e., AMI excluding SCD cases), considering the ratio of the IR of $\mathrm{AMI}$ in the highest prefecture to the lowest prefecture was 2.0 in Japan. ${ }^{25}$ It is interesting to note that a previous study has been limited to a ratio of AMI to UAP in Japan (UAP: AMI $=1: 1.56$; UAP was $39 \%$ of the total number of AMI and UAP) based on a hospital-based design. ${ }^{9}$

Furthermore, the number of hospitalized patients with AMI in 2015 was reported to be 68,850 by the Japanese registry of all cardiac and vascular diseases (JROAD), which assesses clinical activity of almost all teaching hospitals with cardiovascular beds and is certified by the Japanese Circulation Society. ${ }^{26}$ This was similar to the number of hospitalized patients with AMI $(\sim 60,000)$ calculated by the age- and sex-specific IRs of hospitalized patients with AMI in the present study and the population size aged $\geq 30$ years in Japan in 2015. The differences in the number of hospitalized patients with AMI between the JROAD report and the present study could be due to the present study having focused on patients with first-onset AMI aged $\geq 30$ years whereas JROAD included patients regardless of their age or having first-onset AMI. Note that a nation-wide survey showed that UAP was $39 \%$ of the total number of AMI and UAP cases in Japan, ${ }^{9}$ which was different from the UAP proportion (24.6\%) in the present study. However, this comparison is difficult because the previous study included reoccurrence of AMI and UAP, whereas the present study did not. Therefore, we considered that further studies are required to clarify the UAP proportion in ACS patients.

The number of ACS patients aged $\geq 75$ years will likely to increase in Japan considering the proportion of people aged $\geq 75$ years will continue to increase in Japan. ${ }^{11}$ In fact, annual percent increases in the incidence of AMI in Japan were 7.6 for men 8.3 for women; it was 7.02 in people aged $\geq 65$ years in Takashima, Japan, between 1999 and 2001. ${ }^{5}$

\section{Study Limitations and Strengths}

The present study had several limitations. First, we retrospectively reviewed medical records with best efforts to collect data on ACS patients; however, there may have been ACS patients whom we mistakenly excluded from the present study. For example, it is possible that data about some of the critically ill patients were not collected. If this happened, the present IRs would be underestimated. There were 70 patients aged $\geq 85$ years, including 27 patients aged $\geq 90$ years and 4 patients aged $\geq 95$ years in the present study. Additionally, $95.2 \%$ of all cardiogenic OHCA cases were transported to our hospital. Thus, the number of missing ACS and SCD cases was too low to drastically change our conclusion. Second, diagnosis criteria of UAP may not be homogeneous between cardiologists; however, the present study was based on a single hospital that had common diagnosis criteria for UAP, which may have kept the diagnosis homogeneous. Third, according to a report about the fire defense headquarters in Nobeoka, there were 273 patients who suffered from OHCA in Nobeoka city between 2015 and 2017 who were not transported by ambulance, mostly because they had been dead and showed signs of decomposition and/or rigor mortis. Of the 273 , there were 209 patients who suffered from OHCA of unknown causes, of which some might have been cardiogenic. We were unable to confirm whether they were cardiogenic causes as the discovery of the bodies after death was delayed and the bodies were not transported to any hospitals.

The present study had several strengths. First, the present study IRs of ACS were based on a city-wide comprehensive registration. All ACS patients in Nobeoka city are hospitalized in our hospital, which is a single hospital and the only emergency and cardiovascular care center in the city as of 2020, except possible rare cases of patients highly unlikely hospitalized in other hospitals. Second, the present study estimated IRs of ACS considering the aging population of Japan and the proposed and redefined elderly groups (i.e., aged $\geq 75$ years old). ${ }^{15}$ Thus, we believe that the present study IRs can be useful for future superaged societies to secure medical resources and services, test and cure ACS (e.g., percutaneous coronary intervention and cardiac intensive care units), and manage cardiovascular risk factors to prevent ACS deaths (e.g., lowering SBP and LDL). ${ }^{10}$

\section{Conclusion}

In conclusion, the present study measured crude and ageadjusted IRs of hospitalized patients with ACS, AMI, and UAP, hospitalized patients with ACS and SCD, and hospitalized patients with AMI and SCD in Nobeoka, Japan, between 2015 and 2017. These IRs can be useful in developing health strategies to prepare medical resources and measure the effects of population strategy intervention on ACS.

\section{Acknowledgments}

None.

\section{Sources of Funding}

This study was supported by ASAHI KASEI. The funder of this study had no role in study design, data collection, data analysis, interpretation of data, writing of the report, and decision to submit the paper for publication. This study was also supported by the Ministry of Health, Labour and Welfare (Grant Number: H30-JunkankitouIppan-005), and by the Ministry of Health, Labour and Welfare Comprehensive Research on Life-Style Related Diseases including Cardiovascular Diseases and Diabetes Mellitus Program Grant Number: 21FA1012).

\section{IRB Information}

This study was approved by the Miyazaki Prefectural Nobeoka Hospital (20190911-1) and the National Cerebral and Cardiovascular Center (No. M30-007). 


\section{Data Availability}

The deidentified participant data will not be shared because the present study was not a clinical trial.

\section{References}

1. Tunstall-Pedoe H, Kuulasmaa K, Amouyel P, Arveiler D, Rajakangas AM, Pajak A. Myocardial infarction and coronary deaths in the World Health Organization MONICA project: Registration procedures, event rates, and case-fatality rates in 38 populations from 21 countries in four continents. Circulation 1994; 90: 583-612.

2. Nielsen KM, Foldspang A, Larsen ML, Gerdes LU, Rasmussen $\mathrm{S}$, Faergeman O. Estimating the incidence of the acute coronary syndrome: Data from a Danish cohort of 138290 persons. Eur J Cardiovasc Prev Rehabil 2007; 14: 608-614.

3. Taylor MJ, Scuffham PA, McCollam PL, Newby DE. Acute coronary syndromes in Europe: 1-year costs and outcomes. Curr Med Res Opin 2007; 23: 495-503.

4. Antoniades L, Christodoulides T, Georgiou P, Hadjilouca C, Christodoulou E, Papasavas E, et al. Epidemiology of acute coronary syndromes in the Mediterranean island of Cyprus (CYPACS study, Cyprus study of acute coronary syndromes). Hellenic J Cardiol 2014; 55: 139-149.

5. Rumana N, Kita Y, Turin TC, Murakami Y, Sugihara H, Morita Y, et al. Trend of increase in the incidence of acute myocardial infarction in a Japanese population: Takashima AMI Registry, 1990-2001. Am J Epidemiol 2008; 167: 1358-1364.

6. Nakamura M, Tanaka F, Segawa T, Takahashi T, Matsuura Y, Sakai T, et al. Temporal trends in the incidence and clinical features of acute myocardial infarction in a Japanese rural area from 2006 to 2014. Circ J 2017; 81: 1854-1861.

7. Ishikawa S, Kayaba K, Gotoh T, Nago N, Nakamura Y, Tsutsumi $\mathrm{A}$, et al. Incidence of total stroke, stroke subtypes, and myocardial infarction in the Japanese population: The JMS Cohort Study. J Epidemiol 2008; 18: 144-150.

8. Wanezaki M, Watanabe T, Nishiyama S, Hirayama A, Arimoto $\mathrm{T}$, Takahashi $\mathrm{H}$, et al. Trends in the incidences of acute myocardial infarction in coastal and inland areas in Japan: The Yamagata AMI Registry. J Cardiol 2016; 68: 117-124.

9. Yui Y, Hirayama A, Nonogi H, Kimura K, Kodama K, Hosoda $\mathrm{S}$, et al. Unstable angina and non-ST elevation acute coronary syndrome: Epidemiology and current management in Japan (Japan Multicenter Investigation for Cardiovascular Disease-D (JMIC-D) Committee). Circ J 2007; 71: 1335-1347.

10. Ogata S, Nishimura K, Guzman-Castillo M, Sumita Y, Nakai M, Nakao YM, et al. Explaining the decline in coronary heart disease mortality rates in Japan: Contributions of changes in risk factors and evidence-based treatments between 1980 and 2012. Int J Cardiol 2019; 291: 183-188.

11. Population Division UN. World population ageing, 2019: Highlights. New York: Publisher; 2019.

12. Marume K, Nagatomo K, Yamamoto N, Kaichi R, Mori T, Komaki S, et al. Prognostic impact of the presence of on-duty cardiologist on patients with acute myocardial infarction admitted during off-hours. J Cardiol 2020; 76: 184-190.
13. Kimura K, Kimura T, Ishihara M, Nakagawa $\mathrm{Y}$, Nakao K, Miyauchi K, et al. JCS 2018 guideline on diagnosis and treatment of acute coronary syndrome. Circ J 2019; 83: 1085-1196.

14. Braunwald E. Unstable angina: A classification. Circulation 1989; 80: 410-414

15. Ouchi Y, Rakugi H, Arai H, Akishita M, Ito H, Toba K, et al. Redefining the elderly as aged 75 years and older: Proposal from the Joint Committee of Japan Gerontological Society and the Japan Geriatrics Society. Geriatr Gerontol Int 2017; 17: 1045-1047.

16. Nobeoka city. Population in Nobeoka city, Japan: Population by age according to the Basic Resident Register. Homepage of Nobeoka City, Japan 2020. http://www.city.nobeoka.miyazaki. jp/display.php?cont=130415112000 (accessed March 12, 2020).

17. Ministry of Health, Labour and Welfare. Report on the results of the study for the revision of the reference population n.d. https://www.mhlw.go.jp/stf/000020200529_1.html (accessed August 1, 2020).

18. R Core Team. R: A Language and Environment for Statistical Computing. Vienna: R Foundation for Statistical Computing; 2020.

19. Tousek P, Tousek F, Horak D, Cervinka P, Rokyta R, Pesl L, et al. The incidence and outcomes of acute coronary syndromes in a central European country: Results of the CZECH-2 registry. Int J Cardiol 2014; 173: 204-208.

20. Nedkoff LJ, Briffa TG, Preen DB, Sanfilippo FM, Hung J, Ridout $\mathrm{SC}$, et al. Age- and sex-specific trends in the incidence of hospitalized acute coronary syndromes in western Australia. Circ Cardiovasc Oual Outcomes 2011; 4: 557-564

21. Widimsky P, Wijns W, Fajadet J, De Belder M, Knot J, Aaberge $\mathrm{L}$, et al. Reperfusion therapy for ST elevation acute myocardial infarction in Europe: Description of the current situation in 30 countries. Eur Heart J 2010; 31: 943-957.

22. Ueshima H. Explanation for the Japanese paradox: Prevention of increase in coronary heart disease and reduction in stroke. $J$ Atheroscler Thromb 2007; 14: 278-286.

23. Ueshima H, Okayama A, Saitoh S, Nakagawa H, Rodriguez B, Sakata K, et al. Differences in cardiovascular disease risk factors between Japanese in Japan and Japanese-Americans in Hawaii: The INTERLIPID study. J Hum Hypertens 2003; 17: 631-639.

24. Sekikawa A, Willcox BJ, Usui T, Carr JJ, Barinas-Mitchell EJM, Masaki KH, et al. Do differences in risk factors explain the lower rates of coronary heart disease in Japanese versus U.S. women. J Womens Healh (Larchmt) 2013; 22: 966-977.

25. Nishigaki K, Yamazaki T, Fukunishi M, Tanihata S, Fujiwara $\mathrm{H}$, Japanese Coronary Intervention Study Group. Assessment of acute myocardial infarction in Japan by the Japanese Coronary Intervention Study (JCIS) Group. Circ J 2004; 68: 515-519.

26. Yasuda S, Nakao K, Nishimura K, Miyamoto Y, Sumita Y, Shishido T, et al. The current status of Cardiovascular Medicine in Japan: Analysis of a Large Number of Health Record from a Nation-wide Claim-based Database, JROAD-DPC. Circ J 2016; 80: $2327-2335$.

\section{Supplementary Files}

Please find supplementary file(s);

http://dx.doi.org/10.1253/circj.CJ-20-1207 